INFLAMMATION AND INFLAMMATORY BOWEL DISEASE

\title{
Upregulation of matrix metalloproteinases in a model of T cell mediated tissue injury in the gut: analysis by gene array and in situ hybridisation
}

\author{
M T Salmela, T T MacDonald, D Black, B Irvine, T Zhuma, U Saarialho-Kere, \\ S L F Pender
}

See end of article for authors' affiliations

Correspondence to: Dr U Saarialho-Kere, Department of Dermatology, Helsinki University Central Hospital, Meilahdentie 2, 00250 Helsinki, Finland; ulpu.saarialho-kere@ helsinki.fi

Accepted for publication 14 February 2002

\begin{abstract}
Background and aim: Matrix metalloproteinases (MMPs) have been implicated in tissue remodelling and ulceration in inflammatory bowel disease and coeliac disease. Studies to date have concluded that stromelysin 1 is functionally involved in mucosal degradation. However, there are many other MMPs whose function in the gut is currently unknown. This work had two aims: firstly, to use gene array technology to measure changes in MMP and tissue inhibitor of metalloproteinase (TIMP) expression in a model of T cell mediated injury in the gut, and secondly, to correlate data from gene arrays with that generated by in situ hybridisation.

Methods: T cells in explants of human fetal gut were activated with pokeweed mitogen or anti-CD3 plus interleukin 12. Gene array analysis and in situ hybridisation were performed to investigate changes in MMP gene expression.

Results: Both gene array analysis and in situ hybridisation indicated marked upregulation of stromelysin 2 and macrophage metalloelastase expression in the explants associated with mucosal destruction. The arrays also confirmed our previous observation that interstitial collagenase (MMP-1), stromelysin 1 (MMP-3), and gelatinase B (MMP-9) are upregulated but there was no change in MMP-2, $-7,-8,-9,-11,-13,-14-17$, or -19 . Following T cell activation, transcripts for TIMPs were reduced. Conclusions: These results show that there is differential upregulation of MMPs during T cell responses in the gut and suggest that further studies on the role of stromelysin 2 and macrophage metalloelastase may show that they have a functional role. In addition, the increase in MMPs and reduction in TIMPs suggest that the protease/antiprotease balance in the mucosa may determine the extent of mucosal degradation.
\end{abstract}

M atrix metalloproteinases (MMPs) are a group of zinc dependent neutral endopeptidases collectively capable of degrading essentially all components of the extracellular matrix (ECM). ${ }^{2}$ The human MMP gene family contains at least 21 structurally related members. These can be grouped further, based on their structure and substrate specificities, into collagenases (interstitial collagenase, MMP-8 and -13), stromelysins (MMP-3, -7, -10,-11,-12, and -26), gelatinases (MMP-2 and -9), membrane-type MMPs (MMP-14, -15, -16,-17, -24, and -25) and other MMPs (MMP-19, -20,-23, and -28). ${ }^{23}$ They have been implicated as being of pathological significance in the ECM degradation seen in rheumatoid arthritis, osteoarthritis, periodontal disease, atherosclerosis, tumour cell invasion, and metastasis. ${ }^{45}$ In addition, the activities of MMPs are controlled in vivo by their natural inhibitors, the tissue inhibitors of metalloproteinases (TIMPs).

Despite extensive literature on the role of this group of enzymes in cancer and wound repair there have only been a few studies related to disorders of the gastrointestinal tract. Recently, MMPs have been implicated as one of the main factors contributing to mucosal ulceration in inflammatory bowel disease (IBD). ${ }^{6-11}$ Although these diseases are undoubtedly caused by excessive immune reactivity in the mucosa, the end stage effector molecules for mucosal degradation appear to be the MMPs secreted by cytokine activated stromal cells. ${ }^{12}$

We have developed an ex vivo model using fetal gut explants to dissect the mechanism involved in $\mathrm{T}$ cell mediated tissue injury in the gut. ${ }^{13-16}$ Resident lamina propria (LP) T cells can be directly activated by lectins such as pokeweed mitogen (PWM) or a combination of anti-CD3 and interleukin 12 (IL-
12) to produce a T helper cell type 1 response in the LP with increased production of interferon $\gamma$ and tumour necrosis factor $\alpha$ (TNF- $\alpha$ ). Histologically, PWM stimulation causes severe tissue injury with LP degradation and shedding of epithelial cells. Human fetal intestine does not contain any blood borne inflammatory cells, B cells, mast cells, or eosinophils, and therefore it provides an excellent model in which to dissect the biochemical basis of $\mathrm{T}$ cell mediated gut injury. Functional studies on the mechanism of $\mathrm{T}$ cell mediated tissue injury in this model have already shown the involvement of certain MMPs, such as stromelysin 1, in mucosal degradation. ${ }^{12} 1718$ Furthermore, nanomolar concentrations of activated recombinant stromelysin 1 added to fetal gut explants rapidly result in degradation of the LP. ${ }^{12}$ The main source of interstitial collagenase and stromelysin 1 in this model is $\alpha$ smooth muscle actin ( $\alpha$-SMA) positive cells. ${ }^{17}$

We hypothesise that other MMPs and TIMPs may also be upregulated in T cell mediated tissue injury in the gut. In this study, we have therefore used RNA oligonucleotide gene arrays with probe sets complementary to most of the known human MMP and TIMP genes to identify which MMPs were correlated with tissue injury in the gut. We then confirmed the changes in MMP and TIMP gene expression by in situ hybridisation.

Abbreviations: PWM, pokeweed mitogen; IL-12, interleukin-12; IBD, inflammatory bowel disease; ECM, extracellular matrix; LP, lamina propria; $\alpha-S M A, \alpha$ smooth muscle actin; MMP, matrix metalloproteinase; TIMP, tissue inhibitor of metalloproteinase; TNF- $\alpha$, tumour necrosis factor $\alpha$. 
Table 1 Gene array analysis and in situ hybridisation of matrix metalloproteinase (MMP) and tissue inhibitor of metalloproteinase (TIMP) genes in day 4 human fetal gut explant cultures

\begin{tabular}{|c|c|c|c|c|c|c|}
\hline \multirow[b]{2}{*}{ MMP } & \multicolumn{2}{|c|}{ Gene array analysis } & \multicolumn{4}{|c|}{ In situ hybridisation* } \\
\hline & $\begin{array}{l}\text { PWM (fold } \\
\text { change } v \\
\text { controls) }\end{array}$ & $\begin{array}{l}\alpha \text { CD3+IL- } 12 \text { (fold } \\
\text { change } v \text { controls) }\end{array}$ & $\begin{array}{l}\text { Performed in this } \\
\text { study }\end{array}$ & Control & PWM & $\alpha \mathrm{CD} 3+\mathrm{IL}-12$ \\
\hline Collagenase $1(\mathrm{MMP}-1) \dagger$ & 3.8 & 2.6 & Yes & - & +++ & + \\
\hline Gelatinase A (MMP-2) & -1.1 & 1.6 & No & ND & ND & ND \\
\hline Stromelysin 1 (MMP-3) $†$ & 8.2 & 5.7 & Yes & + & +++ & ++ \\
\hline Matrilysin (MMP-7) & -1.9 & -2.0 & Yes & - & ++ & + \\
\hline Neutrophil collagenase (MMP-8) & -1.4 & 1.0 & No & ND & ND & ND \\
\hline Gelatinase B (MMP-9) & 6.2 & 5.5 & No & ND & ND & ND \\
\hline Stromelysin 2 (MMP-10) & 4.0 & 2.6 & Yes & - & +++ & ++ \\
\hline Stromelysin 3 (MMP-11) & -1.1 & 1.1 & No & ND & ND & ND \\
\hline Macrophage metalloelastase (MMP-12) & 11.9 & 7.3 & Yes & + & +++ & ++ \\
\hline Collagenase 3 (MMP13) & 1.2 & 1.5 & Yes & - & - & + \\
\hline MT1-MMP (MMP-14) & -1.0 & -1.2 & Yes & + & + & + \\
\hline MT2-MMP (MMP-15) & -1.4 & -1.0 & No & ND & ND & ND \\
\hline MT3-MMP (MMP-16) & -1.7 & -1.4 & No & ND & ND & ND \\
\hline MT4-MMP (MMP-17) & 1.7 & 2.7 & No & ND & ND & ND \\
\hline MMP-19 & -1.2 & 1.1 & No & ND & ND & ND \\
\hline TIMP-1 & -1.4 & -1.1 & Yes & +++ & + & + \\
\hline TIMP-2 & -1.0 & -1.1 & No & ND & ND & ND \\
\hline TIMP-3 & 1.5 & 1.1 & Yes & +++ & + & + \\
\hline TIMP-4 & 1.7 & 1.1 & No & ND & ND & ND \\
\hline
\end{tabular}

The gene arrays detected MMP and TIMP genes in day 4 cultured explants, the fold change over control were quantified by computer.

*In situ hybridisation signal was evaluated using dark field microscopy.

Signal strength was assessed as follows: - , no detectable specific signal; +, specific signal in few cells; ++, specific signal in moderate number of cells; +++ , specific signal in a high number of cells

† In situ hybridisation data were shown in our previous study. ${ }^{17}$

ND, not determined; PWM, pokeweed mitogen; IL-12, interleukin-12.

\section{MATERIALS AND METHODS}

\section{Organ culture of human fetal small intestine}

Second trimester human fetal small intestine was obtained within two hours of surgical termination from the Medical Research Council Tissue Bank, Hammersmith Hospital (London, UK). All specimens used in this study were aged between 15 and 16 weeks of gestation. This study received ethical approval from the Hackney and District Health Authority (London, UK).

Culture of human fetal small intestine explants in serum free medium was performed as previously described. ${ }^{13}{ }^{14}$ Mucosal T cells were activated by PWM ( $10 \mu \mathrm{g} / \mathrm{ml}$, Sigma Chemical Co., St Louis, Missouri, USA) or anti-CD3 plus IL-12 ( $5 \mathrm{ng} / \mathrm{ml}$; R\&D System, Minneapolis, Minnesota, USA) at the onset of culture. All samples were harvested on day 4, at which point cells are still alive and viable. ${ }^{13}$ Day 0 tissue samples were also used to quantify MMP and TIMP baseline expressions.

\section{Gene chip analysis}

Total RNA was extracted from at least 100 human fetal intestine explants of each culture condition (unstimulated, PWM stimulated, and anti-CD3+IL-12) by a single step modification of a standard RNA purification protocol using TRIzol reagent (Life Technologies, Rockville, Maryland, USA). The quality of total RNA was checked and then RNA was further purified by a poly-A column before gene array analysis. For each of the samples, $10 \mu \mathrm{g}$ of total RNA were used to synthesise double stranded DNA using the Superscript Choice System (Life Technologies). In vitro transcription using double stranded cDNA as a template in the presence of biotinylated UTP and CTP was carried out using an Enzo BioArray High Yield RNA Transcript Labelling Kit (Affymetrix and Enzo Diagnostic). Biotin labelled cRNA was purified, fragmented, and hybridised to the HuGeneFL arrays (the Affymetrix Hu6800 gene chips; Affymetrix, Santa Clara, California, USA and Enzo Diagnostic, Farmingdale, New York, USA) which contain probes against 6800 human genes including MMP $1-3,7-17,-19$, and TIMP 1-4. The arrays were washed and stained with streptavidin-phycoerythrin on an Affymetrix Fluidic Station and scanned on an Affymetrix GeneArray Scanner. Data was analysed using Affymetrix GeneChip Expression Analysis Software (version 3.1).

\section{In situ hybridisation}

Production and specificity of the antisense human stromelysin 2, macrophage metalloelastase, collagenase 3, matrilysin, TIMP-1, and TIMP-3 probes have been described elsewhere. $^{7819-2226}$ A 1240 bp fragment of MTl-MMP CDNA $^{23}{ }^{24}$ was subcloned to a pGEM vector containing an SP6 RNA polymerase recognition element. When linearised with Bgl II, an antisense RNA probe could be transcribed in vitro containing 405 bp from 3'UTR of the MT1-MMP cDNA. As a control for non-specific hybridisation, sections were hybridised with ${ }^{35} \mathrm{~S}$-labelled sense RNA from a bovine tropoelastin cDNA. The validity of this probe as a negative control has been confirmed by northern blotting ${ }^{25}$ and by in situ hybridisation ${ }^{26}$ assays. The cDNAs were transcribed in vitro using a commercial kit (Promega Corp., Madison, Wisconsin, USA) and labelled with ${ }^{35} \mathrm{~S}$-UTP, as previously described..$^{27}$

Following deparaffinisation and rehydration, $5 \mu \mathrm{m}$ sections were pretreated with $1 \mu \mathrm{g} / \mathrm{ml}$ of proteinase $\mathrm{K}$ and washed in $0.1 \mathrm{M}$ triethanolamine containing $0.25 \%$ acetic anhydride. Subsequently, sections were hybridised with probes (2.5$5 \times 10^{4} \mathrm{cpm} / \mu \mathrm{l}$ of hybridisation buffer) and washed under stringent conditions, including treatment with RNAse A. ${ }^{25}$ Autoradiography was carried out for 20-45 days. All samples were processed in at least two experiments and were independently analysed by two experienced investigators. Samples shown previously to be positive for stromelysin 2 (chronic wounds), macrophage metalloelastase (sarcoid granulomas), collagenase 3 (squamous cell carcinomas), matrilysin (sweat gland tumours), MTI-MMP (breast cancers), and TIMP-3 (colon cancers) were used as positive controls.

\section{Immunostaining}

Immunostaining was performed using the avidin-biotinperoxidase complex technique on sections parallel to those 


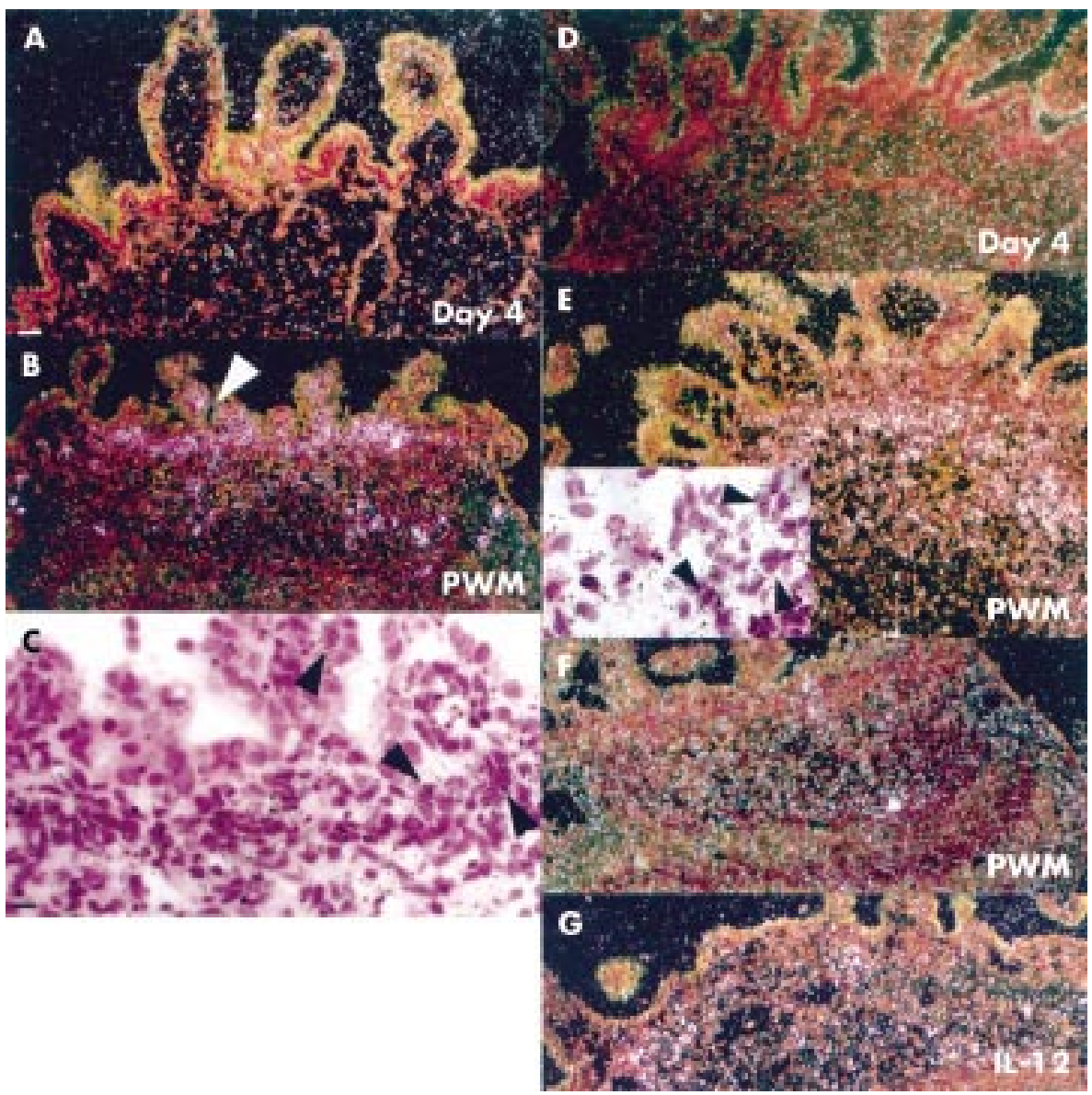

Figure 1 Stromelysin 2 and matrilysin. (A) Control sample cultured for four days was negative for stromelysin 2 mRNA. (B) Stromelysin 2 expressing cells were located in the lamina propria in a pokeweed mitogen (PWM) stimulated explant (arrowhead depicts the area in (C)). (C) High magnification bright field of stromal stromelysin 2 positive cells. (D) There was no upregulation of matrilysin expression in control explants. (E) Expression of matrilysin in a PWM stimulated explant which still showed villi. (Inset E) High magnification of matrilysin mRNA positive cells. (F) No matrilysin expression was seen in explants where PWM induced extensive mucosal degradation. (G) Expression of matrilysin in an anti-CD-3+interleukin 12 (IL-12) stimulated explant. Scale bars: $50 \mu \mathrm{m}$ (A, B, D-G); 12.5 rm (C, inset E).

used for in situ hybridisation. ${ }^{26}$ Aminoethylcarbazole was used as the chromogenic substrate. $\alpha$-SMA (6582; Bio-Makor, Rehovot, Israel) monoclonal antibody was used to detect myofibroblasts. Tissues were counterstained with haematoxylin.

\section{RESULTS}

\section{Gene array analysis}

Gene array analysis was performed on unstimulated, PWM stimulated, and anti-CD3+IL-12 stimulated human fetal gut culture explants (table 1). The intensity of the arrays from the stimulated samples was compared with those from unstimulated samples, and the fold change versus the unstimulated controls was recorded and shown. Any change in gene expression greater than 2.5 times that of controls was considered significant. In PWM stimulated explants, interstitial collagenase, stromelysin 1, gelatinase B, stromelysin 2, and macrophage metalloelastase were upregulated by more than 2.5 times compared with controls. In explants stimulated with a combination of anti CD-3 and IL-12, the same results were obtained, but there was additional upregulation of MMP-17. Matrilysin, neutrophil collagenase, stromelysin 3, collagenase 3, MT-1, -2, -3, and TIMP-1, -2, -3, and -4 gene expression remained unchanged or was downregulated after stimulation (table 1).

\section{In situ hybridisation}

Evaluation of in situ hybridisation signal for MMPs and TIMPs was performed using dark field microscopy; signal strength was assessed by two experienced investigators (table 1). We have previously performed in situ hybridisation for interstitial collagenase and stromelysin 1 in this model and repeated this work as an internal control (table 1). However, we carried out in situ hybridisation to analyse expression of stromelysin 2 and macrophage metalloelastase which showed the most pronounced increase. We also analysed matrilysin, collagenase 3, membrane type 1 MMP, and TIMP-1 and -3, although they did not change according to the array.

\section{Stromelysin 2 (MMP-10)}

No stromelysin 2 expression was detected in day 0 control tissue (data not shown) or in unstimulated day 4 control tissue (fig 1A), and no stromelysin 2 positive epithelial cells were seen (data not shown). In PWM stimulated explants, stromelysin 2 was abundantly expressed in the LP underneath the epithelium in the locality of stromal fibroblast/macrophagelike cells (figs 1B, C). In anti-CD3+IL-12 stimulated explants, stromelysin 2 was expressed in occasional $\alpha$-SMA negative cells of the LP underneath the mucosal epithelium (data not shown). Based on the location of upregulated stromelysin 2 in PWM and anti-CD3+IL-12 stimulated explants (in areas of mucosa showing extensive injury), its expression may be a contributing factor in epithelial cell shedding and mucosal degradation (fig lB).

\section{Matrilysin (MMP-7)}

We have previously shown that the extent of the injury in the mucosal microenvironment depends on the number of $\mathrm{T}$ cells 


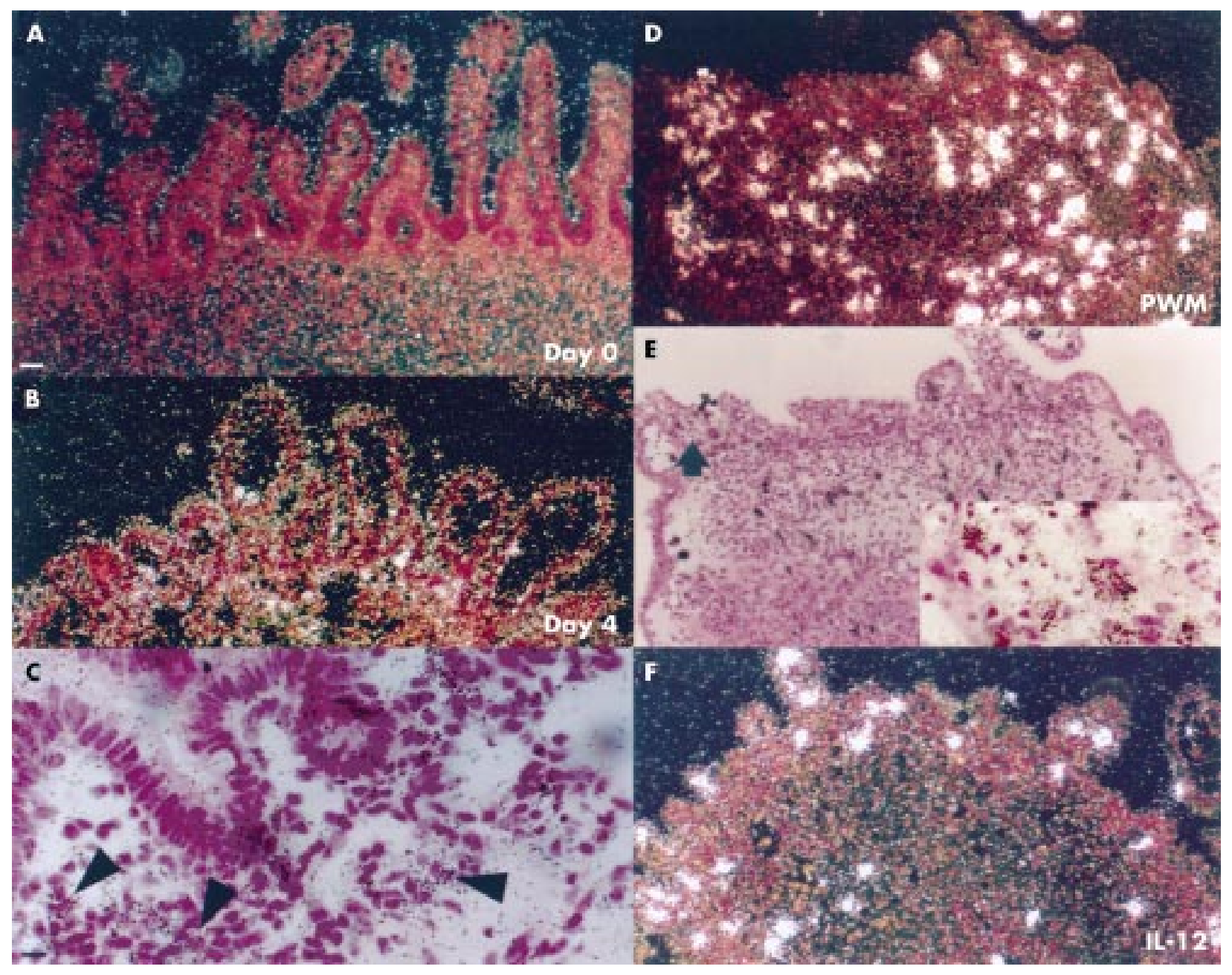

Figure 2 Macrophage metalloelastase expression. (A) No macrophage metalloelastase expression was seen in day 0 tissue. (B) Occasional cells positive for macrophage metalloelastase mRNA were seen in unstimulated control explants cultured for four days. (C) High magnification bright field image of stromal macrophage metalloelastase mRNA positive cells in unstimulated control sample (day 4). (D) Expression of macrophage metalloelastase by stromal cells in a pokeweed mitogen (PWM) stimulated explant. (E) Corresponding bright field image (arrow shows the area in inset (E)). (F) Expression of macrophage metalloelastase in anti-CD3+interleukin 12 (IL-12) stimulated explant. Scale bars: $50 \mu \mathrm{m}(\mathrm{A}, \mathrm{B}, \mathrm{D}, \mathrm{E}, \mathrm{F}) ; 12.5 \mu \mathrm{m}(\mathrm{C}$, insert E).

resident at a particular site in the mucosa. Thus even in explants stimulated with PWM or anti-CD3+IL-12, there is some heterogeneity in the tissue injury. Day 0 tissue (data not shown) and unstimulated control tissue cultured for four days were negative for matrilysin mRNA (fig ID). In PWM stimulated explants, matrilysin expression was detected in the myofibroblast zone (fig lE) where villi were still intact. Interestingly, in explants where the tissue suffered severe injury, very little matrilysin expression was seen (fig lF). Generally, the matrilysin positive area partly colocalised with regions positive for stromelysin 2 (fig lB, IE). The location and magnitude of signal was similar in anti-CD-3+IL-12 treated explants (fig lG).

\section{Macrophage metalloelastase (MMP-12)}

There was no macrophage metalloelastase expression in day 0 control tissue (fig 2A) but occasional metalloelastase positive cells were seen underneath the epithelium and in the LP in control samples cultured for four days (fig 2B, C). In PWM stimulated and anti-CD3+IL-12 stimulated explants, macrophage metalloelastase was strongly expressed throughout the mucosa (figs 2D-F).

MT1-MMP (MMP-14)

In day 4 control samples, there was low expression of MMP-14 (fig 3A). No expression was detected in fetal tissue at the onset of culture (data not shown). In PWM stimulated explants (fig 3B) and CD3+IL-12 stimulated explants (fig 3C; inset C), MT1 expression was only slightly upregulated.

\section{Collagenase 3 (MMP-13)}

No expression of collagenase 3 was detected in PWM stimulated explants (fig 3E). Day 0 (data not shown) and day 4 control samples (fig 3D) were also negative for collagenase 3 mRNA. Collagenase 3 was detected only in occasional fibroblast-like cells in the LP of anti-CD-3+IL-12 explants (fig 3F; inset f).

\section{TIMP-1 and -3}

TIMP-1 mRNA expression was abundantly detected in day 0 tissue samples (fig 4A). In unstimulated day 4 control explants, strong signal for TIMP-1 mRNA was detected in stromal cells in the LP. In PWM or anti-CD-3+IL-12 stimulated specimens, few positive cells for TIMP-1 could be seen after four days of culture. TIMP-3 was also abundantly expressed in day 0 (fig 4D, E) and unstimulated samples (fig 4F). However, expression was also clearly downregulated after PWM (fig 4G) or anti-CD-3+IL-12 stimulation (data not shown).

\section{DISCUSSION}

To gain further knowledge on the biological functions of various MMPs and their inhibitors in experimental models 


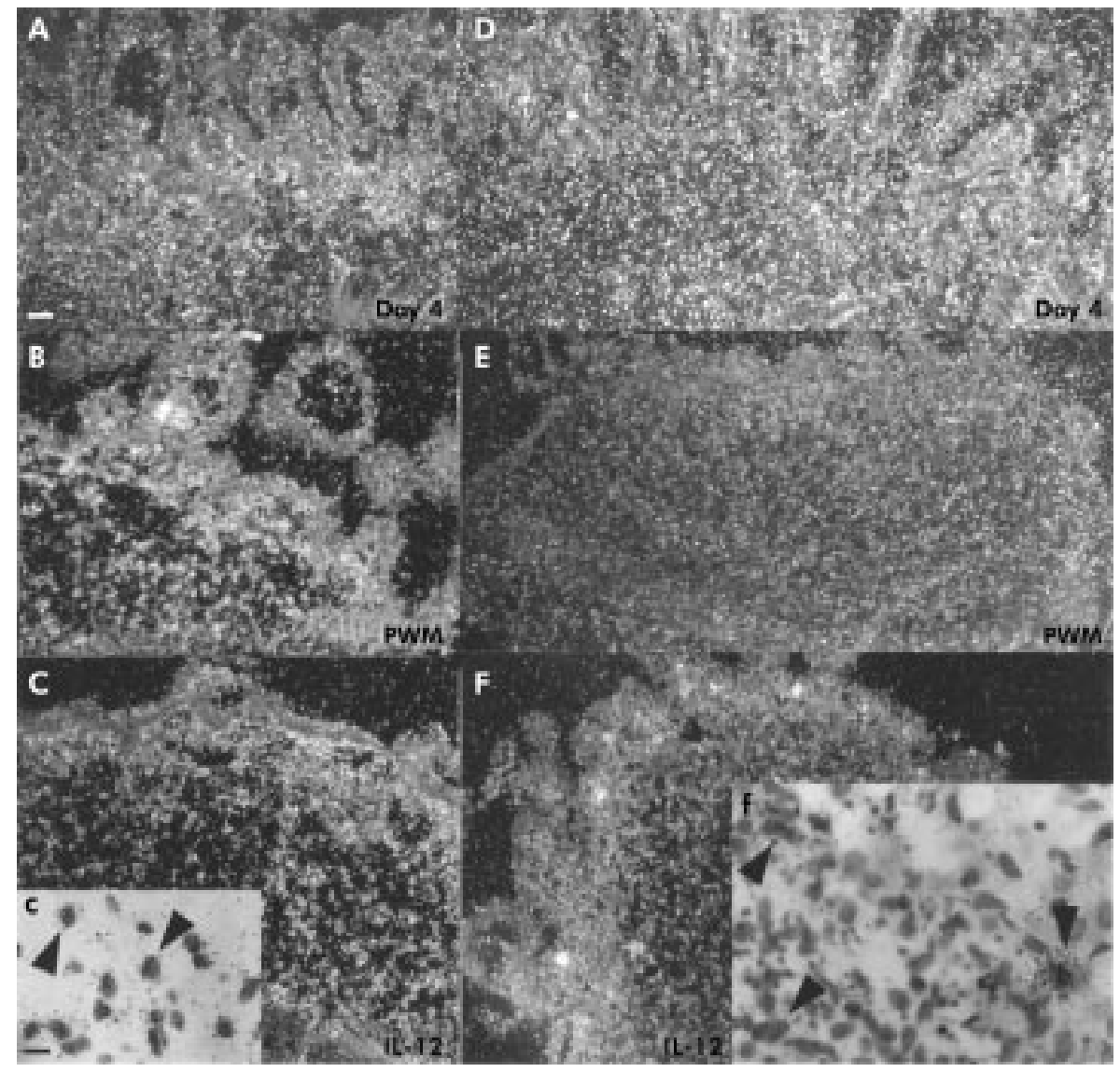

Figure 3 MT1-matrix metalloproteinase (MMP) and collagenase 3. (A) Very low MT1-MMP expression was seen in unstimulated control explants cultured for four days. (B) MT1-MMP was increased in the stroma of a pokeweed mitogen (PWM) treated explant. (C) Stromal cells in lamina propria expressed MT1 in a fetal gut explant stimulated with anti-CD3+interleukin 12 (IL-12). (Inset c) High magnification bright field image showing stromal MT1-MMP mRNA positive cells. (D) Collagenase 3 mRNA was not expressed in day 4 unstimulated control samples. (E) Collagenase 3 was not detected in a PWM stimulated sample. (F) Collagenase 3 mRNA in occasional stromal cells of an anti-CD-3+IL-12 treated explant. (Inset f) High magnification bright field image showing collagenase 3 mRNA positive cells. Scale bars: $50 \mu \mathrm{m}$ (A-F); $12.5 \mu \mathrm{m}$ (inset $c$, inset $f$ ).

relevant to IBD, their expression patterns were studied by gene array analysis and in situ hybridisation in an ex vivo model of T cell injury in the human gut. Expression of MMPs is mainly transcriptionally regulated. Thus it can be assumed that MMP protein levels will correlate with mRNA expression in vitro ${ }^{28}$ although we did not carry out these studies.

In this study, both gene array analysis and in situ hybridisation showed that stromelysin 2 expression was upregulated in cells of the LP following $\mathrm{T}$ cell activation by PWM and anti-CD3+IL-12. A fourfold increase over controls was detected in PWM stimulated fetal gut explants by the gene array. In parallel, in situ hybridisation showed that the signal for stromelysin 2 was particularly high where mucosal damage was most severe. We also found by in situ hybridisation that there was high stromelysin 2 expression in day 1 PWM stimulated explants when tissue damage began (unpublished data), suggesting the potential involvement of stromelysin 2 in tissue destruction rather than remodelling. We have previously demonstrated the presence of stromelysin 2 in the stroma of IBD ulcers in the vicinity of T cells. ${ }^{8}$ In cutaneous wound repair and IBD, stromelysin 2 is also expressed by migrating epithelial cells. ${ }^{8}{ }^{29}$ Stromelysin 2 can degrade type IV collagen, laminin, and fibronectin and may, in excess, digest the epithelial cells off their basement membrane.

Macrophage metalloelastase was also markedly upregulated in the arrays. Gene expression was upregulated 12-fold in PWM stimulated explants and sevenfold in antiCD3+IL-12 explants. Its expression could not be found in day 0 samples but when the tissue had been cultured for four days there were positive cells in the villi in control tissue (fig 2B). This probably reflects a macrophage response to tissue injury caused by dissecting tissue explants. Macrophage metalloelastase was highly expressed in macrophages following $\mathrm{T}$ cell activation of both types. Induction of metalloelastase may facilitate movement of macrophages out of the vasculature into the surrounding stroma and to sites of inflammation. Interestingly, very strong expression of macrophage metalloelastase is detected under the shedding epithelium in IBD in vivo. ${ }^{8}$ Furthermore, macrophage metalloelastase may contribute substantially to the degradation of connective tissues in these models since in vitro it degrades type IV collagen, entactin, fibronectin, laminin-1, proteoglycans, and elastin. ${ }^{30}$

Matrilysin expression was detectable in unstimulated explants but its expression was slightly downregulated in the stimulated cultures analysed by gene array. However, more matrilysin expression was detectable in day 4 PWM than day 4 anti-CD3+IL-12 stimulated explants by in situ hybridisation and the region of maximal signal partly colocalised with that of stromelysin 2. Although it is possible to detect total expression within controls by gene array, in situ hybridisation is sensitive enough to detect localised increases in expression. Interestingly, no signal was seen in areas of total mucosal destruction but rather in regions where villi were still intact. There was no signal detected in day 1 stimulated explant when tissue damage began (unpublished data). This suggests that matrilysin may function in tissue remodelling/repair rather than in degradation: although this requires experimental confirmation, it may well degrade proteoglycans, gelatins, 


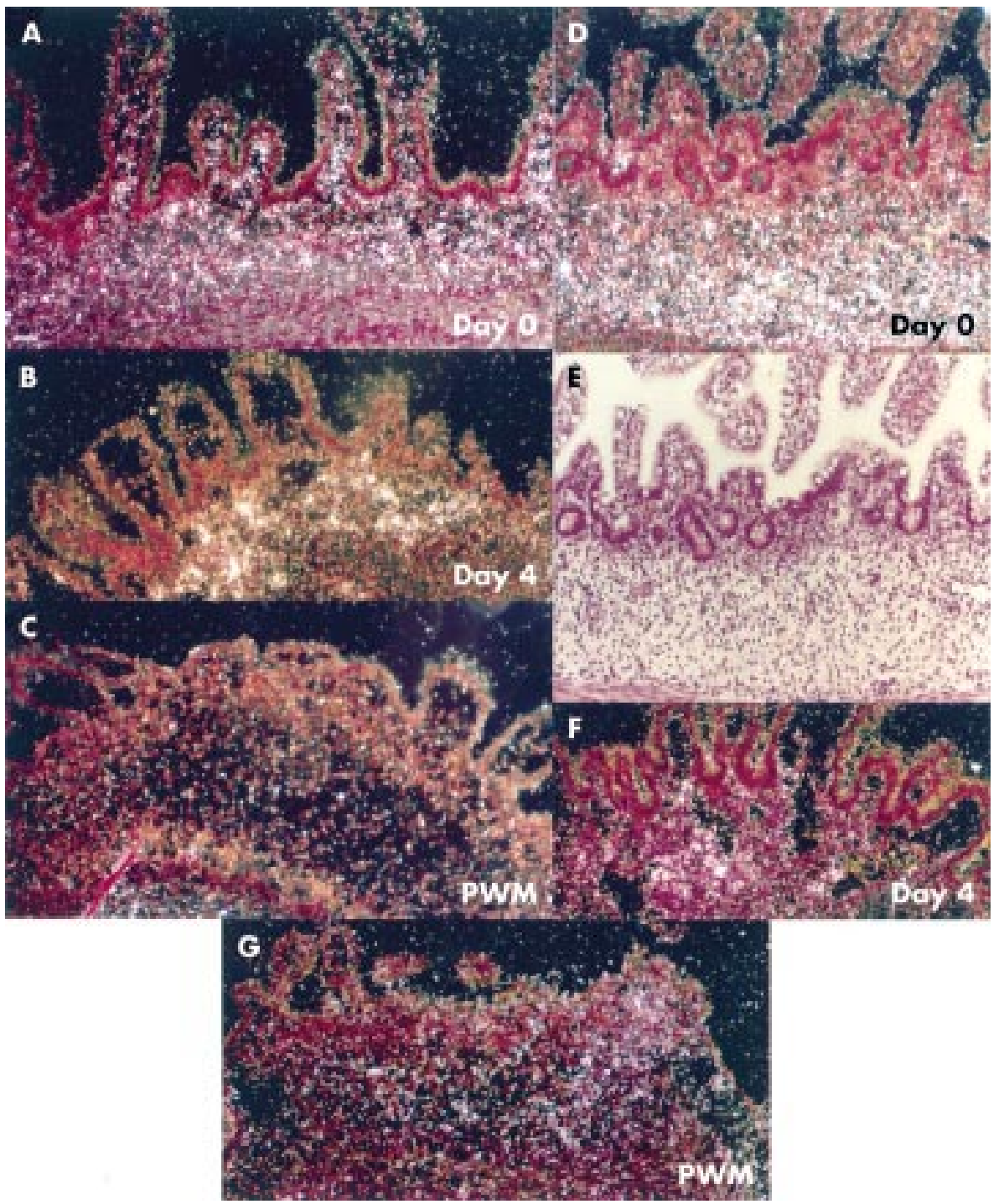

Figure 4 Tissue inhibitors of metalloproteinases (TIMPs)-1 and -3. (A) TIMP-1 expression in day 0 tissue. (B) Expression of TIMP-1 after four days of culture in control explant. (C) No signal for TIMP-1 mRNA was seen in a pokeweed mitogen (PWM) stimulated explant. (D) Abundant TIMP-3 expression in day 0 tissue. (E) Corresponding bright field image. (F) High numbers of cells expressing TIMP-3 mRNA were still seen after culturing control explants for four days. (G) TIMP-3 expression was clearly downregulated in PWM stimulated explant. Scale bars: 50 rm $(A-G)$.

or elastin in these models. ${ }^{31}$ Matrilysin can be activated in extracellular spaces by stromelysin 1 , which is known to be produced in these explants, ${ }^{12}$ and is often expressed by epithelial cells of the intestine and skin but rarely produced by mesenchymal cells in vivo. ${ }^{32}$ In our previous studies of IBD, matrilysin was only expressed by enterocytes bordering colonic and ileal ulcers. ${ }^{7}$ Production by stromal cells has not been demonstrated in cutaneous or intestinal cells. However, macrophages in culture can express matrilysin. ${ }^{32}$ IL- $1 \beta$ and TNF- $\alpha$, which are abundant in PWM explants, do not influence macrophage secretion of matrilysin. ${ }^{31}$

Collagenase 3 and MT1-MMP were not upregulated in the arrays and were also not markedly enhanced by in situ hybridisation. However, MTl-MMP has often been associated with gelatinase $\mathrm{A}$ and collagenase 3 activation in cancer invasion. ${ }^{33}{ }^{34}$ In IBD, MTl-MMP is very abundantly expressed by mesenchymal cells colocalising with stromelysin $1 .{ }^{24}$ Von Lampe and colleagues ${ }^{35}$ demonstrated increased expression of MT1-MMP by northern analysis in ulcerative colitis. Also, in contrast with our previous findings in IBD stroma which demonstrated abundant collagenase 3 producing fibroblasts beneath the neutrophilic infiltrate of the ulcer bed, ${ }^{8}$ colla- genase 3 was not dramatically increased in fetal gut explants. Collagenase 3 is upregulated in fibroblasts by transforming growth factor $\beta$ and TNF- $\alpha$, but not by IL- $1 \beta .^{36}$ There may be at least two reasons for the discrepancies found in MMP expression between the explants and IBD tissue in vivo: firstly, tissues are of fetal origin and, secondly, the system does not contain blood borne inflammatory cells, B cells, mast cells, or eosinophils.

An imbalance between proteinases and their inhibitors has been implicated in the pathobiology of chronic ulcers. We have previously shown that while certain MMPs were upregulated in PWM stimulated explants, TIMP-1 and -2 concentrations remained unchanged. ${ }^{10}$ However, in this study, TIMP-1 and -3 expression detected by in situ hybridisation was highest in the uncultured day 0 control samples and diminished in the treated explants, suggesting that at least interstitial collagenase, gelatinase A, stromelysin 1 , gelatinase B, and collagenase $-3^{37}$ can function in these models without impedance from TIMP-1 and -3. Expression of both TIMPs in day 4 control samples was lower than in day 0 samples but clearly higher compared with tissues in which $\mathrm{T}$ cell activation was induced. TIMP-3 is known to bind to ECM. As in IBD 
samples, ${ }^{8}$ no TIMPs were found in the epithelia of explants stimulated with PWM or anti-CD3+IL-12.

In experimental models, it has been demonstrated that mucosal injury is triggered after activation of $\mathrm{T}$ cells which are capable of secreting at least gelatinase A, gelatinase B, stromelysin 2, and collagenase $3 .^{38}{ }^{39}$ Surprisingly, it has not been possible to demonstrate MMP mRNAs in cells with typical morphology of $\mathrm{T}$ lymphocytes (small round cells with large dark nucleus). ${ }^{17}$ Thus it may well be that direct contact of $\mathrm{T}$ lymphocytes with mononuclear cells or other cell types ${ }^{40}$ or proinflammatory cytokines secreted by $\mathrm{T}$ cells contributes to the matrix destruction observed.

In conclusion, our work shows that in addition to collagenase 1 and stromelysin 1 , stromelysin 2 and macrophage metalloelastase may also contribute to gastrointestinal ulceration during T cell mediated inflammation. Expression of MMP inhibitors, TIMP-1 and -3 was downregulated following $\mathrm{T}$ cell activation, suggesting that an imbalance between proteases and inhibitors favours epithelial shedding and ulceration. Finally, the use of gene array technology allowed us to analyse expression of most MMPs and all TIMPs simultaneously and provided a framework for further functional studies in this model of tissue damage.

\section{ACKNOWLEDGEMENTS}

We thank Drs Veli-Matti Kähäri, Steven Shapiro, Lynn Matrisian, and Jouko Lohi for plasmids, Dr Marja-Liisa Karjalainen-Lindsberg for her pathology expertise, and Mrs Alli Tallqvist and Birgitta Arteva for their skilful technical assistance. We also thank Dr L Wong at the MRC tissue bank for collecting human fetal tissue. We are grateful to Dr Marilyn Lewis (Bioinformatics Department) and Drs Frank Burslem and Claire Johnson (Genetic Technologies Department) at Pfizer Global Research and Development for discussion and consultation of the gene array data.

This work also received financial support from the Commission of the European Communities, specific RTD programme "Quality of Life and Management of Living Resources", QLK1-CT-1999-00037, "Evaluation of the prevalence of coeliac disease and its genetic components in the European population" (it does not necessarily reflect its views and in no way anticipates the Commission's future policy in this area).

Grant support was provided by the Academy of Finland, the Sigrid Juselius Foundation, Finska Läkaresällskapet and Helsinki University Central Hospital Research Funds, Crohn's in Childhood Research Association (CICRA, UK), and Biotechnology and Biological Sciences Research Council (BBSRC, UK).

\section{Authors' affiliations}

M T Salmela, U Saarialho-Kere, Department of Dermatology, Helsinki University Central Hospital, Helsinki, Finland

T T MacDonald, S L F Pender, Division of Infection, Inflammation, and Repair, School of Medicine, University of Southampton, Southampton SO16 6YD, UK

D Black†, B Irvine, T Zhuma, Pfizer Global Research and Development, Sandwich, Kent CT13 9NJ, UK

†Present address: Organon Research Centre, Newhouse, Lanarkshire MLI 5SH, UK

\section{REFERENCES}

1 Birkedal-Hansen H, Moore WG, Bodden MK, et al. Matrix metalloproteinases: a review. Crit Rev Oral Biol Med 1993;4:197-250.

2 Nagase $\mathrm{H}$ and Woessner JF. Matrix metalloproteinases. J Biol Chem 1999:274:21491-4

3 de Coignac $\mathbf{A B}$, Elson G, Delneste $Y$, et al. Cloning of MMP-26. A novel matrilysin-like proteinase. Eur J Biochem 2000;267:3323-9.

4 Brown PD. Matrix metalloproteinases in gastrointestinal cancer. Gut 1998;43:161-3

5 Kahari VM, Saarialho-Kere U. Matrix metalloproteinases and their inhibitors in tumour growth and invasion. Ann Med 1999;31:34-45.

6 Bailey CJ, Hembry RM, Alexander A, et al. Distribution of the matrix metalloproteinases stromelysin, gelatinases $A$ and $B$, and collagenase in Crohn's disease and normal intestine. J Clin Pathol 1994;47:1 13-16.

7 Saarialho-Kere UK, Vaalamo M, Puolakkainen P, et al. Enhanced expression of matrilysin, collagenase, and stromelysin-1 in gastrointestinal ulcers. Am J Pathol 1996;148:519-26.
8 Vaalamo M, Karjalainen-Lindsberg ML, Puolakkainen $\mathrm{P}$, et al. Distinct expression profiles of stromelysin-2 (MMP-10), collagenase-3 (MMP-13), macrophage metalloelastase (MMP-12), and tissue inhibitor of metalloproteinases-3 (TIMP-3) in intestinal ulcerations. Am J Pathol 1998; 152:1005-14.

9 Baugh MD, Perry M, Hollander AP, et al. Matrix metalloproteinase levels are elevated in inflammatory bowel disease. Gastroenterology $1999 ; 117: 814-22$.

10 Heuschkel RB, MacDonald TT, Monteleone G, et al. Imbalance of stromelysin-1 and TIMP-1 in the mucosal lesions of children with inflammatory bowel disease. Gut 2000;47:57-62.

11 Louis E, Ribbens C, Godon A, et al. Increased production of matrix metalloproteinase- 3 and tissue inhibitor of metalloproteinase- 1 by inflamed mucosa in inflammatory bowel disease. Clin Exp Immunol 2000;120:241-6.

12 Pender SL, Tickle SP, Docherty A, et al. A major role for matrix metalloproteinases in T cell injury in the gut. J Immunol 1997; 158:1582-90.

13 MacDonald TT, Spencer J. Evidence that activated mucosal T cells play a role in the pathogenesis of enteropathy in human small intestine. J Exp Med 1988;167:1341-9.

14 Lionetti $\mathbf{P}$, Breese $E$, Braegger $C P$, et al. T-cell activation can induce either mucosal destruction or adaptation in cultured human fetal small intestine. Gastroenterology 1993;105:373-81.

15 Lionetti P, Spencer J, Breese EJ, et al. Activation of mucosal V beta 3+ T cells and tissue damage in human small intestine by the bacterial superantigen, Staphylococcus aureus enterotoxin B. Eur J Immunol 1993;23:664-8

16 Pender SL, Lionetti P, Murch SH, et al. Proteolytic degradation of intestinal mucosal extracellular matrix after lamina propria $T$ cell activation. Gut 1996:39:284-90.

17 Pender SL, Breese EJ, Gunther U, et al. Suppression of T cell-mediated injury in human gut by interleukin-10: role of matrix metalloproteinases. Gastroenterology 1998;115:573-83

18 Pender SL, Fell JM, Chamow SM, et al. A p55 TNF receptor immunoadhesin prevents $T$ cell-mediated intestinal injury by inhibiting matrix metalloproteinase production. J Immunol 1998;160:4098-103.

19 Saarialho-Kere UK, Pentland AP, Birkedal-Hansen H, et al. Distinct populations of basal keratinocytes express stromelysin-1 and stromelysin-2 in chronic wounds. J Clin Invest 1994;94:79-88.

20 Vaalamo $M$, Mattila L, Johansson N, et al. Distinct populations of stromal cells express collagenase-3 (MMP-13) and collagenase-1 (MMP-1) in chronic ulcers but not in normally healing wounds. J Invest Dermatol 1997; 109:96-101.

21 McDonnell S, Navre M, Coffey RJ, et al. Expression and localization of the matrix metalloproteinase pump-1 (MMP-7) in human gastric and colon carcinomas. Mol Carcinog 1991;4:527-33

22 Airola K, Ahonen M, Johansson N, et al. Human TIMP-3 is expressed during fetal development, hair growth cycle, and cancer progression. $J$ Histochem Cytochem 1998;46:437-47.

23 Lohi J, Lehti K, Westermarck J, et al. Regulation of membrane-type matrix metalloproteinase-1 expression by growth factors and phorbo 12-myristate 13-acetate. Eur J Biochem 1996;239:239-47.

24 Pender SL, Salmela MT, Monteleone G, et al. Ligation of alpha4ss 1 integrin on human intestinal mucosal mesenchymal cells selectively up-regulates membrane type-1 matrix metalloproteinase and confers a migratory phenotype. Am J Pathol 2000;157:1955-62.

25 Prosser IW, Stenmark KR, Suthar M, et al. Regional heterogeneity of elastin and collagen gene expression in intralobar arteries in response to hypoxic pulmonary hypertension as demonstrated by in situ hybridization. Am J Pathol 1989;135:1073-88.

26 Saarialho-Kere UK, Chang ES, Welgus HG, et al. Distinct localization of collagenase and tissue inhibitor of metalloproteinases expression in wound healing associated with ulcerative pyogenic granuloma. J Clin Invest 1992:90: 1952-7.

27 Saarialho-Kere UK, Kovacs SO, Pentland AP, et al. Cell-matrix interactions modulate interstitial collagenase expression by human keratinocytes actively involved in wound healing. J Clin Invest 1993;92:2858-66

28 Graham MF, Willey A, Zhu YN, et al. Corticosteroids repress the interleukin 1 beta-induced secretion of collagenase in human intestinal smooth muscle cells. Gastroenterology 1997;113:1924-9.

29 Vaalamo M, Weckroth M, Puolakkainen P, et al. Patterns of matrix metalloproteinase and TIMP-1 expression in chronic and normally healing human cutaneous wounds. Br J Dermatol 1996;135:52-9.

30 Chandler S, Cossins J, Lury J, et al. Macrophage metalloelastase degrades matrix and myelin proteins and processes a tumour necrosis factor-alpha fusion protein. Biochem Biophys Res Commun 1996;228:421-9.

31 Murphy G, Cockett MI, Ward RV, et al. Matrix metalloproteinase degradation of elastin, type IV collagen and proteoglycan. A quantitative comparison of the activities of $95 \mathrm{kDa}$ and $72 \mathrm{kDa}$ gelatinases, stromelysins- 1 and -2 and punctuated metalloproteinase (PUMP). Biochem J 1991;277:277-9.

32 Wilson CL, Matrisian LM. Matrilysin: an epithelial matrix metalloproteinase with potentially novel functions. Int J Biochem Cell Biol 1996;28: 123-36

33 Seiki M. Membrane-type matrix metalloproteinases. APMIS 1999;107: 137-43.

34 Johansson N, Vaalamo M, Grenman S, et al. Collagenase-3 (MMP-13) is expressed by tumor cells in invasive vulvar squamous cell carcinomas. Am J Pathol 1999;154:469-80. 
35 von Lampe B, Barthel B, Coupland SE, et al. Differential expression of matrix metalloproteinases and their tissue inhibitors in colon mucosa of patients with inflammatory bowel disease. Gut 2000;47:63-73.

36 Ravanti L, Hakkinen L, Larjava $H$, et al. Transforming growth factor-beta induces collagenase-3 expression by human gingival fibroblasts via p38 mitogen-activated protein kinase. J Biol Chem 1999:274:37292-300.

37 Apte SS, Olsen BR, Murphy G. The gene structure of tissue inhibitor of metalloproteinases (TIMP)-3 and its inhibitory activities define the distinct TIMP gene family. J Biol Chem 1995;270:14313-18.
38 Willmroth $\mathbf{F}$, Peter $\mathrm{HH}$, Conca $\mathrm{W}$. A matrix metalloproteinase gene expressed in human T lymphocytes is identical with collagenase 3 from breast carcinomas. Immunobiology 1998;198:375-84.

39 Leppert D, Waubant E, Galardy R, et al. T cell gelatinases mediate basement membrane transmigration in vitro. J Immunol 1995; 154:4379-89.

40 Lacraz S, Isler P, Vey E, et al. Direct contact between T lymphocytes and monocytes is a major pathway for induction of metalloproteinase expression. J Biol Chem 1994;269:22027-33. 